\title{
Enraizamento de inhame em meios MS e carvão ativado
}

\section{Rooting yam in MS medium and activated charcoal}

\section{Karine da Silva SIMÕES ${ }^{1}$; Lucymeire Souza Moraes LINO²; Antonio da Silva SOUZA Sebastião de Oliveira e SILVA ${ }^{4}$; Carlos Alberto da Silva LEDO ${ }^{5}$}

${ }^{1}$ Autor para correspondência: Mestre em Ciências Agrárias. Universidade Federal do Recôncavo da Bahia -
UFRB. karinesimoes01@hotmail.com
${ }^{2}$ Pós-doutoranda. Embrapa Mandioca e Fruticultura - Embrapa. Ismorais@yahoo.com.br
${ }^{3}$ Pesquisador. Embrapa Mandioca e Fruticultura - Embrapa. antonio.silva-souza@embrapa.br
${ }^{4}$ Professor Visitante Senior. Universidade Federal do Recôncavo da Bahia - UFRB. ssilva3000@gmail.com
${ }^{5}$ Pesquisador. Embrapa Mandioca e Fruticultura - Embrapa. carlos.ledo@embrapa.br

Recebido em: 01-10-2013; Aceito em: 13-04-2014

\section{Resumo}

Microestacas foram cultivadas em: metade da concentração de sais e vitaminas do meio de cultura MS $(1 / 2 \mathrm{MS})+0 \mathrm{~g} \mathrm{~L}^{-1}$ de carvão ativado (CA); $1 / 2 \mathrm{MS}+0,5 \mathrm{~g} \mathrm{~L}^{-1} \mathrm{CA} ; 1 / 2 \mathrm{MS}+1,0 \mathrm{~g} \mathrm{~L}^{-1} \mathrm{CA} ;(\mathrm{MS})+$ $0 \mathrm{~g} \mathrm{~L}^{-1} \mathrm{CA} ; \mathrm{MS}+0,5 \mathrm{~g} \mathrm{~L}^{-1} \mathrm{CA}$, e $\mathrm{MS}+1,0 \mathrm{~g} \mathrm{~L}^{-1} \mathrm{CA}$. $\mathrm{O}$ efeito do meio de cultura só se mostrou significativo nas concentrações de 0 e $1 \mathrm{~g}$ de carvão ativado para a altura das plantas. $O$ número de raízes formadas nas plantas de inhame cultivadas in vitro não apresentou diferença estatística entre as concentrações do meio de cultura MS e doses de carvão ativado estudadas; entretanto, no meio $1 / 2 \mathrm{MS}$ com adição de $1 \mathrm{~g} \mathrm{~L}^{-1}$ de carvão ativado, foi a mais favorável no desenvolvimento das raízes. Concluiu-se que, para um melhor desenvolvimento da parte aérea e do sistema radicular das plantas, recomenda-se o uso de metade da concentração de sais e vitaminas do meio MS, e que o maior número de raízes ocorre em meio acrescido com carvão ativado.

Palavras-chave adicionais: Dioscorea rotundata Poir; microestacas; micropropagação.

\begin{abstract}
Yam microshoots were grown in : half the concentrations of salts and vitamins of the MS medium (1/2 MS) $+0 \mathrm{~g} \mathrm{~L}^{-1}$ of activated charcoal (AC), $1 / 2 \mathrm{MS}+0.5 \mathrm{~g} \mathrm{~L}^{-1} \mathrm{AC}, 1 / 2 \mathrm{MS}+1.0 \mathrm{~g} \mathrm{~L}^{-1} \mathrm{AC}, \mathrm{MS}+0 \mathrm{~g} \mathrm{~L}^{-1} \mathrm{AC}, \mathrm{MS}+$ $0.5 \mathrm{~g} \mathrm{~L}^{-1} \mathrm{AC}$, and $\mathrm{MS}+1.0 \mathrm{~g} \mathrm{~L}^{-1} \mathrm{AC}$. The effect of the culture medium was significant only at concentrations of 0 and $1 \mathrm{~g}$ of activated charcoal for plant height. The differences in culture medium concentration and doses of activated charcoal caused no significant differences in the number of roots formed in yam plants growing in vitro. But the medium $1 / 2 \mathrm{MS}+1.0 \mathrm{~g} \mathrm{~L}^{-1} \mathrm{AC}$ was more favorable for root development. It was concluded that for a better development of shoots and roots of yam plants it is recommended the use of half the concentration of salts and vitamins of the MS medium and that the greatest number of roots occurs in a medium supplemented with activated charcoal.
\end{abstract}

Additional keywords: Dioscorea rotundata; microshoots; micropropagation.

\section{Introdução}

O inhame (Dioscorea spp.), uma monocotiledônea da família Dioscoreaceae, espécie tuberosa de alto potencial, rica em vitaminas do complexo B (contendo altos teores de tiamina, riboflavina, niacina), vitamina $A$, ácido ascórbico, carboidratos e grãos de amido (responsáveis pela alta digestibilidade), tem sido considerado um alimento básico para a população, podendo ainda ser utilizado na agroindústria (SANTOS, 1996).

Um dos grandes entraves na propagação vegetativa é a qualidade da muda, que normalmente dissemina pragas e doenças. Como alternativa, a biotecnologia vem contribuindo para as pesquisas realizadas, pelo uso de diferentes técnicas, destacando-se a micropropagação para a produção de material propagativo sadio (SOUZA et al., 2006).
Cada espécie de planta requer um meio de cultura específico para ter um desenvolvimento considerado normal; por isso, torna-se fundamental o estudo da composição em sais minerais, suplementos orgânicos e o balanceamento e o tipo de reguladores vegetais para a indução da diferenciação da parte aérea ou da raiz das plantas (SANTOS et al., 2005).

$\mathrm{Na}$ maioria das vezes, os explantes micropropagados não iniciam o processo de enraizamento em meios com concentrações altas de sais, apesar das auxinas presentes. Tais condições tendem a inibir todas as fases do enraizamento, particularmente o crescimento de raízes. Assim, concentrações de sais no meio, reduzidas para $1 / 2,1 / 3$ ou $1 / 4$, possibilitam melhor enraizamento (HU \& WANG, 1983).

Para GEORGE \& DEBERGH (2008), o 
carvão ativado, embora não seja um regulador de crescimento, tem sido utilizado com frequência com esse objetivo, em doses que variam de 0,1 a $0,5 \%$ para melhorar ou regular o crescimento de plantas in vitro, porém sua presença pode promover ou inibir o crescimento, dependendo da espécie e do tecido utilizados (GEORGE \& SHERRINGTON, 1984). Vários são os trabalhos que citam o emprego de carvão ativado na micropropagação de espécies frutíferas, como videira, ameixeira, framboeseira, morangueiro, macieira, abacaxizeiro e bananeira (ROY, 1995).

Entre os efeitos proporcionados pela adição do carvão ativado ao meio de cultura, estão: promoção de ambiente escuro, que favorece o enraizamento; adsorção de substâncias inibitórias produzidas pelo próprio meio ou explante; adsorção de reguladores de crescimento e de outros compostos orgânicos; e liberação de substâncias naturalmente presentes no carvão que beneficiam o crescimento in vitro das culturas (GEORGE \& SHERRINGTON, 1984).

Diante da importância que a micropropagação vem assumindo na multiplicação de espécies em todo o mundo para produção de mudas isenta de pragas e doenças, este trabalho teve como objetivo avaliar o enraizamento in vitro de plantas de Inhame-da-Costa em meio de cultura (MS) com diferentes concentrações de sais, vitaminas e carvão ativado.

\section{Material e métodos}

Microestacas de plantas de Inhame-daCosta preestabelecidas in vitro foram utilizadas como fonte de explantes iniciais e cultivadas em seis meios de cultura: 1 - concentração normal de sais e vitaminas do meio de cultura MS (MURASHIGE \& SKOOG, 1962) + $0 \mathrm{~g} \mathrm{~L}^{-1}$ de carvão ativado; 2 - MS + $0,5 \mathrm{~g} \mathrm{~L}^{-1}$ de carvão ativado; 3 - MS + 1,0 $\mathrm{g} \mathrm{L}^{-1}$ de carvão ativado; 4- metade da concentração de sais e vitaminas do $M S(1 / 2 \mathrm{MS})+0 \mathrm{~g} \mathrm{~L}^{-1}$ de carvão ativado; 5- $1 / 2 \mathrm{MS}+0,5 \mathrm{~g} \mathrm{~L}^{-1}$ de carvão ativado; $61 / 2 \mathrm{MS}+1,0 \mathrm{~g} \mathrm{~L}^{-1}$ de carvão ativado. Todos os meios de cultura foram complementados com $30 \mathrm{~g} \mathrm{~L}^{-1}$ de sacarose, solidificado com $7 \mathrm{~g} \mathrm{~L}^{-1}$ de Ágar e o pH ajustado para 5,8.

As culturas foram mantidas em sala de crescimento, com temperatura de $27 \pm 1^{\circ} \mathrm{C}$, luminosidade de $30 \mu \mathrm{mol} \mathrm{m} \mathrm{m}^{-1}$ e fotoperíodo de 16 horas. Aos 30 dias, avaliaram-se as variáveis: altura de planta $(\mathrm{cm})$, número de folhas, número de raízes, número de nós e gemas/nó por explante. Para a avaliação do número de raízes foi estabelecida uma escala de 0 (zero) a 2 (dois), em que, 0: nenhuma raiz; 1: 1 a 10 raízes, e 2: mais de 10 raízes.

Foi utilizado o delineamento experimental inteiramente casualizado, em esquema fatorial $3 \times 2$ (3 doses de carvão ativado e 2 concen- trações de meio MS), com 13 repetições, sendo cada parcela experimental constituída de um tubo de ensaio contendo uma microestaca. As médias dos tratamentos foram comparadas pelo teste de Tukey, a $5 \%$ de probabilidade. As variáveis número de folhas, número de raízes, número de nós e gemas/nó foram transformadas para raiz quadrada de $(x+0,5)$, visando ao atendimento das pressuposições da análise de variância, e calculados os coeficientes de correlação de Spearman entre as variáveis estudadas. As análises estatísticas foram realizadas pelo programa estatístico SAS Statistical Analysis System (SAS INSTITUTE, 2004).

\section{Resultados e discussão}

O resumo da análise de variância da altura de planta $(A L T)$, em $\mathrm{cm}$, número de folhas (NFO), número de raízes (NRA), número de nós (NNO) e número de gemas/nó (GNO) de plantas de Inhame-da-Costa, cultivadas em diferentes concentrações do meio de cultura MS e carvão ativado, é apresentado na Tabela 1.

Observa-se que houve efeitos significativos $(p<0,05)$ para a correlação meio de cultura $x$ carvão ativado, nas variáveis: altura de plantas, número de folhas e número de raízes, indicando que existem diferenças entre os tratamentos estudados.

Para altura das plantas (ALT) de inhame, foi observado que houve diferença significativa entre as concentrações do meio de cultura MS e as doses 0 e $1 \mathrm{~g} \mathrm{~L}^{-1}$ de carvão ativado (Tabela 2). Quando se relacionaram carvão ativado e doses do meio MS, observou-se que só houve diferença significativa quando se utilizou $1 \mathrm{~g} \mathrm{~L}^{-1}$ de carvão ativado em qualquer das doses de meio de cultura MS. Esses resultados concordam com VILLA et al. (2007), que observaram o maior comprimento da parte aérea $(6,188 \mathrm{~cm})$ no meio MS associado a $1,0 \mathrm{~g} \mathrm{~L}^{-1}$ de carvão ativado, após 70 dias de cultivo.

KOWALSKI \& STADEN (2001) relatam que a utilização de $2,0 \mathrm{~g} \mathrm{~L}^{-1}$ de carvão ativado no meio de cultura proporcionou melhor crescimento das brotações de Podocarpus henkelii. Da mesma forma, MOHAMED (2001) verificou aumento no comprimento de plântulas de milho com a adição de carvão ativado ao meio.

Não houve diferenças significativas para as diferentes concentrações do meio MS nem para as dosagens de carvão ativado, quando foi estudado o número de folhas na micropropagação do inhame (Tabela 3). No entanto, foi observado em porta-enxerto de Prunus pérsica $\times P$. amygdalus, que o maior número de folhas ocorreu com a adição de carvão ativado no meio de cultura (SOTIROPOULOS \& FOTOPOULOS, 2005). 
Tabela 1 - Resumo da análise de variância da altura de planta (ALT), em cm, número de folhas (NFO), número de raízes (NRA), número de nós (NNO) e número de gemas/ nó (GNO) de plantas de Inhame- da-Costa (Dioscorea rotundata.) cultivadas em diferentes concentrações do meio de cultura MS e carvão ativado. Summary table of the analysis of variance of plant height (ALT), in cm, number of leaves (NFO), number of roots (NRA), number of nodes (NNO), and number of buds per node (GNO) of yam plants grown in different concentrations of the MS medium and activated charcoal.

\begin{tabular}{lcccccc}
\hline \multirow{2}{*}{ FV } & \multirow{2}{*}{ GL } & \multicolumn{5}{c}{ QM } \\
\cline { 3 - 7 } & & ALT & NFO & NRA & NNO & GNO \\
\hline Meio & 1 & $8,5813^{* *}$ & $0,1393^{\text {ns }}$ & $0,9294^{*}$ & $0,0010^{\text {ns }}$ & $2,6913^{* *}$ \\
Carvão Ativado & 2 & $0,0471^{\text {ns }}$ & $0,4394^{\text {ns }}$ & $0,0757^{\text {ns }}$ & $0,0316^{\text {ns }}$ & $0,2061^{\text {ns }}$ \\
Meio x Carvão & 2 & $5,6910^{* *}$ & $1,4127^{*}$ & $1,2005^{\star *}$ & $0,1370^{\text {ns }}$ & $0,6368^{\text {ns }}$ \\
Erro & 102 & 0,8956 & 0,4260 & 0,1377 & 0,2435 & 0,3565 \\
\hline CV (\%) & & 44,13 & 33,15 & 35,44 & 29,42 & 47,42 \\
Média Geral & & 2,1444 & 3,8149 & 0,7593 & 2,5463 & 1,2593 \\
\hline
\end{tabular}

${ }^{* *} \mathrm{e}^{*}$ significativo a 1 e $5 \%$ de probabilidade, respectivamente, pelo teste de $\mathrm{F}$ e ${ }^{\text {ns }}$ não significativo.

Tabela 2 - Valores médios de altura de plantas $(\mathrm{cm})$ de Inhame-da-Costa cultivadas em diferentes concentrações do meio de cultura MS e de carvão ativado. Mean yam plant height as influenced by different concentrations of the MS medium and activated charcoal.

\begin{tabular}{cccc}
\hline \multirow{2}{*}{ Meios } & \multicolumn{4}{c}{ Concentrações de carvão ativado $(\mathrm{g})$} \\
\cline { 2 - 4 } & 0 & 0,5 & 1 \\
\hline $1 / 2 \mathrm{MS}$ & $1,92 \mathrm{aB}^{*}$ & $2,33 \mathrm{aAB}$ & $2,75 \mathrm{aA}$ \\
$\mathrm{MS}$ & $2,31 \mathrm{aA}$ & $1,80 \mathrm{aAB}$ & $1,47 \mathrm{bB}$ \\
\hline
\end{tabular}

*Médias seguidas pelas mesmas letras, minúsculas nas colunas e maiúsculas nas linhas, não diferem estatisticamente entre si, pelo teste de Tukey, a $5 \%$ de probabilidade.

Tabela 3 - Valores médios do número de folhas (NFO) de plantas de Inhame-da-Costa cultivadas em diferentes concentrações do meio de cultura MS e de carvão ativado. Mean yam plant number of leaves as influenced by different concentrations of the MS medium and activated charcoal.

\begin{tabular}{cccc}
\hline \multirow{2}{*}{ Meios } & \multicolumn{4}{c}{ Concentrações de carvão ativado $(\mathrm{g})$} \\
\cline { 2 - 4 } & 0 & 0,5 & 1 \\
\hline $1 / 2 \mathrm{MS}$ & $3,91 \mathrm{aA}^{*}$ & $2,74 \mathrm{aA}$ & $4,45 \mathrm{aA}$ \\
MS & $4,71 \mathrm{aA}$ & $4,18 \mathrm{aA}$ & $3,17 \mathrm{aA}$ \\
\hline
\end{tabular}

*Médias seguidas pelas mesmas letras, minúsculas nas colunas e maiúsculas nas linhas, não diferem estatisticamente entre si, pelo teste de Tukey, a $5 \%$ de probabilidade.

VILLA et al. (2007) averiguaram que, mesmo na ausência de carvão ativado, foi constatada a presença de folhas em plantas de amoreira-preta e no porta-enxerto de videira, obtendo-se maior número $(15,17$ e 5,76$)$, respectivamente. Esse resultado pode ser atribuído ao fato de o carvão ativado favorecer a formação de maior número de folhas, porém de tamanho reduzido, apresentando menor número de segmentos nodais e folhas, ou seja, a ausência do carvão ativado não se tornou um fator limitante para o desenvolvimento das folhas de inhame.

O número de raízes formadas nas plântulas do inhame não apresentou diferença estatística na concentração $1 / 2 \mathrm{MS}$; entretanto, no meio MS sem carvão ativado, foi mais favorável o desenvolvimento das raízes, onde, segundo a escala utilizada para avaliação, as plantas produziram a média de 10 raízes (Tabela 4). Con- firmando os resultados encontrados por ERIG et al. (2004), que mostraram que a ausência do carvão ativado no meio de cultura possibilitou melhor crescimento de raízes em um experimento com pera, assim como NICOLOSO et al. (2001) também verificaram que a percentagem de enraizamento em Pfaffia glomerata não foi influenciada pela presença de carvão ativado no meio de cultura.

REDDY et al. (2001) observaram que plantas de Decalepis hamiltonii tiveram um enraizamento de $100 \%$ em meio MS adicionado de $4,4 \mathrm{mg} \mathrm{L}^{-1}$ de AIB mais $0,25 \%$ de carvão ativado. NIRMAL et al. (2003) também observaram melhores resultados no enraizamento in vitro de Cinnamomum camphora em meio WPM, com a adição de AIB associado ao carvão ativado. Embora o meio de cultura testado não tenha apresentado a auxina sintética AIB em sua 
composição, que é uma das mais utilizadas em eficácia para promover o enraizamento, foi comprovado que, mesmo com a ausência do AIB e do carvão ativado, é possível promover o enraizamento in vitro do inhame

O número de gemas/nó não foi influenciado pela interação das diferentes concentrações dos meios de cultura MS com as doses do carvão ativado; no entanto, pode-se observar que, entre os meios de cultura utilizados, o MS foi o que obteve melhores respostas para o parâmetro estudado (Tabela 5).

A adição de carvão ativado ao meio de cultura é utilizada no intuito de otimizar o crescimento e o desenvolvimento do número de gemas/nó na cultura de tecidos. VIEITEZ et al. (2009), contudo, para Bauhinia cheilantha, nas concentrações de $0 ; 1,0$ e 2,0 $\mathrm{g} \mathrm{L}^{-1}$ de carvão ativado testadas, não se observaram efeito favorável para a variável em análise, independentemente da concentração de regulador utilizada (GUTIÉRREZ et al., 2011). Assim como para o estudo com Inhame-da-Costa, o carvão ativado não favoreceu o melhor desenvolvimento in vitro do número de gemas/nó

VILLA et al. (2007) verificaram que a adição de carvão ativado ao meio de cultura MS proporcionou inibição da multiplicação dos brotos e do segmento nodal em explantes in vitro de duas frutíferas: amoreira-preta (Rubus spp.) cv. Ébano e videira (Vitis spp. L.) usada como portaenxerto. Embora o carvão ativado não tenha proporcionado maior desenvolvimento do número de gemas para o inhame, esse regulador não se tornou o fator de inibição para a espécie em estudo, uma vez que foi possível obter plantas para essa variável tanto em meio com a presença, como na ausência do carvão ativado.

Tabela 4 - Valores médios do número de raízes de plantas de Inhame-da-Costa cultivadas em diferentes concentrações do meio de cultura MS e do carvão ativado. Mean yam plant number of roots as influenced by different concentrations of the MS medium and activated charcoal.

\begin{tabular}{cccc}
\hline \multirow{2}{*}{ Meios } & \multicolumn{3}{c}{ Concentrações de carvão ativado $(\mathrm{g})$} \\
\cline { 2 - 4 } & 0 & 0,5 & 1 \\
\hline $1 / 2 \mathrm{MS}$ & $0,45 \mathrm{aA}^{*}$ & $0,91 \mathrm{aA}$ & $1,32 \mathrm{aA}$ \\
MS & $1,12 \mathrm{aA}$ & $0,35 \mathrm{bB}$ & $0,11 \mathrm{bB}$ \\
\hline
\end{tabular}

*Médias seguidas pelas mesmas letras, minúsculas nas colunas e maiúsculas nas linhas, não diferem estatisticamente entre si, pelo teste de Tukey, a $5 \%$ de probabilidade.

Tabela 5 - Valores médios do número de gemas/nó de plantas de Inhame-da-Costa cultivadas em diferentes concentrações do meio de culturas MS. Mean yam plant number of buds per node as influenced by different concentrations of the MS medium and activated charcoal.

\begin{tabular}{cc}
\hline Meios & № de gemas/nó \\
\hline $1 / 2 \mathrm{MS}$ & $1,11 \mathrm{~b}$ \\
MS & $1,42 \mathrm{a}$
\end{tabular}

Médias seguidas pelas mesmas letras não diferem estatisticamente entre si, pelo teste de Tukey, a 5\% de probabilidade.

Tabela 6 - Correlação de Spearman da altura de planta (ALT), em $\mathrm{cm}$, número de folhas (NFO), número de raízes (NRA), número de nós (NNO) e número de gemas/nó (GNO) de plantas cultivadas de Inhame-da-Costa em diferentes concentrações do meio de cultura MS e de carvão ativado. Spearman correlation for plant height (ALT), number of leaves (NFO), number of roots (NRA), number of nodes (NNO), and number of buds per node (GNO) of yam plants growing in different concentrations of MS medium and activated charcoal.

\begin{tabular}{lcccc}
\hline Variáveis & NFO & NRA & NNO & GNO \\
\hline ALT & $0,49^{* *}$ & $0,45^{* *}$ & $0,37^{* *}$ & $-0,12^{\text {ns }}$ \\
NFO & - & $0,09^{\text {ns }}$ & $0,66^{* *}$ & $0,26^{* *}$ \\
NRA & - & - & $-0,04^{\text {ns }}$ & $-0,31^{* *}$ \\
NNO & - & - & - & $-0,31^{* *}$ \\
\hline
\end{tabular}

** significativo a $1 \%$ de probabilidade, respectivamente, pelo teste $t ;{ }^{\text {ns }}$ não significativo a $5 \%$ de probabilidade.

O desenvolvimento do sistema radicular a partir da formação de raízes adventícias, em plantas propagadas vegetativamente sob condições in vitro ou in vivo, é um processo de grande complexidade e envolve diversos fatores que ainda não estão completamente elucidados (SOUZA \& PEREIRA, 2007). Com isso, é necessário fazer outros estudos adicionando outros reguladores de crescimento associados ao carvão ativado para comprovar qual a melhor inte- 
ração para promover o enraizamento in vitro.

Não existiram correlações lineares entre as variáveis ALT e GNO, NFO e NRA, NRA e NNO, enquanto entre as variáveis ALT e NFO, ALT e NRA, ALT e NNO houve uma correlação baixa e positiva, significativa a $1 \%$ de probabilidade, pelo teste t. Já entre as variáveis NRA e GNO, NNO e GNO, houve uma correlação baixa, negativa e significativa a $1 \%$ de probabilidade, pelo teste de $t$ (Tabela 6 ).

\section{Conclusões}

Para um melhor desenvolvimento da parte aérea e do sistema radicular das plantas de inhame in vitro, recomenda-se o uso de metade da concentração de sais e vitaminas do meio de cultura MS;

O maior número de raízes ocorre em meio acrescido com carvão ativado.

\section{Referências}

ERIG, A. C.; SCHUCH, M. W.; BRAGA, E. J . B Enraizamento in vitro de pereira (Pyrus communis L.) cv. Carrick, Santa Maria. Ciência Rural, Santa Maria, v.34, n.1, p.275-277, 2004. Disponível em: <http://www.scielo.br/pdf/cr/v34n1/a43v34n1.pdf.> Acesso em: 09 mar. 2013.

GEORGE, E. F.; SHERRINGTON, P. D. Plant propagation by tissue culture. Basingstone: Exegetics, 1984.709p.

GEORGE, E. F; DEBERGH, P. C. Micropropagation: uses and methods. In: GEORGE, E. F; HALL, M. A; KLERK, G. J. Plant propagation by tissue culture. Netherlands: Springer, 2008. 355p.

GUTIERREZ, I. E. M.; NEPOMUCENO, C. F.; LEDO, C. A. S.; SANTANA, J. R. F. Regeneração in vitro via organogênese direta de Bauhinia cheilantha, Santa Maria. Ciência Rural, Santa Maria, v.41, n.2, p.260-265, 2011. Disponível em: http://www.scielo.br/pdf/cr/v41n2/a870cr3845.pdf> . Acesso em: 25 mar. 2013.

HU, C. Y.; WANG, P. J. Meristem shoot tip and bud culture. In: EVANS, D. A.; SHARP, W. R.; AMMIRATO, P. V.; YAMADA, Y. Handbook of plant cell cultures. New York: Macmillan, 1983. v.1, p.177- 227.

KOWALSKI, B.; STADEN, J. Micropropagation of Podocarpus henkelii and $P$. elongates. South African Journal of Botany, Pretoria, v.67, p.362-366, 2001. Disponível em: <http://www.ajol.info/índex.php/sajb/article/view /20446.>. Acesso em: 25 mai. 2013.
MOHAMED,Y. Y. Influence of agar and activated charcoal on uptake of gibberellin and plant morphogenesis in vitro. In vitro Cellular and Developmental Biology Plant, London, v.37, p.204-205, 2001. Disponível em: <http://www.springer.com/lifesciences/plantscie nces/ 11627>. Acesso em: 7 mai. 2013.

MURASHIGE, T.; SKOOG, F. A. A revised medium for a rapid growth and bioassays with tobacco tissues cultures. Plant Physiology, Minneapolis, v.15, p.473-479, 1962. Disponível em: <http://www.onlinelibary.wiley.com/doi/10111/j1399. 3054.x.pdf.>. Acesso em: 14 mai. 2013.

NICOLOSO, F. T.; ERIG, A. C.; MARTINS, C. F.; RUSSOWSKI, D. Micropropagação do ginseng brasileiro [Pfaffia glomerata (Spreng.) Pedersen]. Revista Brasileira de Plantas Medicinais, Botucatu, v.3, p.11-18, 2001. Disponível em: $<$ http://www.scielo.br/pdf/cargo/v27n1/a10v27n1.p df.>. Acesso em: 7 mai. 2013.

NIRMAL, B. K.; SAJINA, A.; MINOO, D.; JOHN, C. Z.; MINI, P. M.; TUSHAR, K. V.; REMA, J.; RAVINDRAN, P. N. Micropropagation of camphor tree (Cinnamomum camphora). Plant Cell, Tissue and Organ Culture, Dordrecht, v.74, p.179-83, 2003. Disponível em: <http://www.link.springer.com/article/101023/>. Acesso em: 7 mai. 2013.

REDDY, B. O.; GIRIDHAR, P.; RAVISHANKAR, G. A. In vitro rooting of Decalepis hamiltonii Wight \& Arn, an endangered shrub, by auxins and rootpromoting agents. Current Science, Washington, v.81, p.1479-1482, 2001. Disponível em: <http://www.currentscience.ac.in/downloads/article -id-081-11k.pdf>. Acesso em: 15 mai. 2013.

ROY, G. M. Agriculture. In: ROY, G. M. Activated carbon applications in the food and pharmaceutical industries. Lancaster: Technomic Publishing Company, 1995. cap.3. p.19-42.

SANTOS, E. S. Inhame (Dioscorea spp): aspectos básicos da cultura. João Pessoa: EMEPA-PB, SEBRAE, 1996. 158p.

SAS INSTITUTE. SAS user's guide: statistic: version 9.1.3. Cary: SAS Institute, 2004. 846p.

SANTOS, A. S. A.; MACHADO, I. S.; LEÃO, A. L.; RAMOS, A. A. Concentrações de BAP e TDZ na propagação in vitro de curauá (Ananas erectifolius L.B.Smith): a influência das citocininas sintéticas na cultura de tecido. Revista de Biotecnologia Ciência \& Desenvolvimento, Brasília, v.8, n.35,p.62-65, $2005 . \quad$ Disponível em: <http://www.biotecnologia.com.br/revista/bio35/co ncentracoes.pdf>. Acesso em: 3 mar. 2014. 
SOTIROPOULOS, T. E.; FOTOPOULOS, S. In vitro propagation of the PR 204/84 peach rootstock (Prunus persica $\times$ P. amygdalus): the effect of BAP, $G A(3)$, and activated charcoal on shoot elongation. European Journal of Horticultural Science, Stuttgart, v.70, p.253- 255, 2005. Disponível em: <http://www.ulmer.de/Artikel.dll/ejhs-2005-04-107>. Acesso em: 10 maio. 2013.

SOUZA, A. S.; COSTA, M. A. P.; SANTOSSEREJO, J. A.; JUNGHANS, T. G.; SOUZA, F. V. D. Introdução à cultura de tecidos de plantas. In: SOUZA, A. S.; JUNGHANS, T. G. (Ed.). Introdução à cultura de tecidos de plantas. Cruz das Almas: Embrapa Mandioca e Fruticultura Tropical, 2006. p.11-37.

SOUZA, A. V.; PEREIRA, A. M. S. Enraizamento de plantas cultivadas in vitro. Revista Brasileira de Plantas Medicinais, Botucatu, v.9, n.4, p.103-117, 2007. Disponível em: <http://www.sbpmed.org.br/downlodo74/artigov9 n4.pdf>. Acesso em: 27 fev. 2013.
SOUZA, A. V.; BERTONI, B. W.; FRANÇA, S. C.; PEREIRA, A. M. S. Micropropagação de Dioscorea multiflora Grised. Ciência e Agrotecnologia, Lavras, v.35, p.92-98, 2011. Disponível em: $<$ http://www.scielo.br/pdf/cargo/v35n1/a11v35n1.pd f.>. Acesso em: 10 mar. 2013.

VILLA, F.; PASQUAL, M.; PIO, L. A. S.; ASSIS, F. A.; TEODORO, G. S. Influência do carvão ativado e BAP na multiplicação in vitro de duas frutíferas de clima temperado. Revista Ceres, Viçosa, MG, v.54, p.118-124, 2007. Disponível em: <http://www.ceres.ufv.br/CERES/revistas/V54N31 2P01907.pdf>. Acesso em: 18 mai. 2013.

VIEITEZ, A. M.; CORREDOIRA, E.; BALLESTER, A.; MUNOZ, F.; DURAN, J.; IBARRA, M. In vitro regeneration of the important North American oak species Quercus alba, Quercus bicolor and Quercus rubra. Plant Cell Tissue and Organ Culture, Dordrecht, v.98, p.135-145, 2009. Disponivel em: <http://digital.csic .es/bitstream/10261/49031/1/SIN\%20>. Acesso em: 20 mai. 2013. 